\title{
Coastline configuration as a determinant of structure in larval assemblages
}

\author{
M. Jessopp ${ }^{1, *}$, O. R. Mulholland ${ }^{2}$, R. McAllen ${ }^{1}$, M. P. Johnson ${ }^{3}$, T. P. Crowe ${ }^{2}$, \\ A. L. Allcock ${ }^{3}$ \\ ${ }^{1}$ Department of Zoology, Ecology and Plant Science, University College Cork, Distillery Fields, North Mall, Cork, Ireland \\ ${ }^{2}$ School of Biology and Environmental Science, University College Dublin, Belfield, Dublin 4, Ireland \\ ${ }^{3}$ School of Biology and Biochemistry, Queen's University Belfast, 97 Lisburn Road, Belfast BT9 7BL, UK
}

\begin{abstract}
The richness and turnover of coastal larval pools set upper limits for biodiversity in coastal systems. For particular local systems, such as embayments, the characteristics of the local larval pool are determined by the relative contributions of locally produced and external larvae. The balance between these sources partially reflects the extent of tidal exchange and is hence related to system size and flushing time. Larvae of benthic marine invertebrates were sampled from 8 bays along the Irish coast to investigate the effect of coastline configuration on the characteristics of the larval pool. Flushing time explained $34.5 \%$ of the variability in species richness from a series of daily samples. Many of the potentially relevant environmental variables are correlated, limiting the potential for individual variables to be examined in isolation. We therefore used a principal components analysis to describe the major patterns in environmental variability across bays. The second principal component separated bays along a gradient of increasing depth, salinity, tidal range and flushing time. Scores along this component were generally better predictors of the larval pool than single variables, explaining as much as $61.2 \%$ of the variation in species richness, diversity and similarity between dates. Deeper bays, with more saline water and longer flushing times, tended to have richer and more diverse larval pools, with a greater consistency in species composition between sample dates. No relationship was found between environmental variables and larval abundance. Our results suggest that flushing time, particularly when in combination with topographic variables, chlorophyll, tidal range and salinity, may be a useful predictor for the richness and turnover of local larval pools.
\end{abstract}

KEY WORDS: Flushing time $\cdot$ Larval retention $\cdot$ Larval dispersal $\cdot$ Larval pool

\section{INTRODUCTION}

Many sedentary or sessile marine species produce free-swimming larvae, which have the potential for dispersal over large distances, linking adult populations across broad spatial scales (Palumbi 2003). This does not imply that the larvae of different species are well mixed in the plankton. Variability in currents, spawning times, larval duration, larval behaviour and location of adult populations cause spatial and temporal patchiness in distribution of larvae (e.g. GonzálezGordillo et al. 2003). Such variability has been recog- nised as a potentially important mechanism for species coexistence. For example, interspecific temporal variability in recruitment may facilitate the coexistence of competing species at a site (a storage effect; Chesson 1985). The size of the local pool of species (sensu Zobel 1997) potentially able to settle at a site sets an upper limit on the diversity at that site, but may also confer local resistance to introduced species (Herben 2005). The characteristics of the local pool, therefore, set the boundaries within which post-recruitment processes such as predation and competition may influence the benthic community at a site. 
Shoreline irregularities such as headlands and embayments can modify local hydrodynamic processes, creating eddies and fronts that affect the dispersion of zooplankton (Alldredge \& Hamner 1980, Lobel \& Robinson 1986, McCulloch \& Shanks 2003). The interaction of such mesoscale features with larval behaviour (Shanks \& Brink 2005, Knights et al. 2007) may explain examples of limited dispersal and local recruitment in species with long planktonic duration (Strathmann et al. 2002, Paris \& Cowen 2004, Cowen et al. 2006). At the scales relevant to larvae, each benthic area has a unique hydrography. Spatially replicated studies are therefore essential to understanding whether particular features (such as bays and headlands) have consistent effects on larval distributions (Archembaut et al. 1998, Archembaut \& Bourget 1999, Palma et al. 2006). A variable potentially useful in describing the likelihood that larvae are retained in bays is the flushing time (Gaines \& Bertness 1992). Flushing time can be defined as the time needed for the total mass of material within the area of interest to be reduced to a factor of $e^{-1}$ (i.e. 0.37) of its original mass (Prandle 1984). In systems where tidal exchange is the main process of water movement, a low flushing time will reduce the chance that a locally produced larva will be retained in the system and increase the potential contribution of externally produced larvae to the local pool.

The general effects of variation in flushing time between bays on the stability and composition of the larval pool are difficult to predict. Three hypotheses can be proposed: (1) Flushing times are not an important factor; biophysical interactions determining larval assemblage structure are too complex and variable for generalities to exist (Sponaugle et al. 2002). Single species and multispecies larval pulses occur, but these are essentially driven by idiosyncratic combinations of physical and biological processes. (2) The richness of larval assemblages will be higher in bays with a low flushing time. This greater richness results when exchange of water with adjacent sites increases the likely range of habitats and source populations that act as larval sources. Spatial averaging across potential larval sources in well-flushed bays will also result in more even distributions of larvae, with fewer recruitment pulses. (3) Bays with long flushing times will have more diverse larval pools due to retention of locally produced larvae and/or due to tidal exchange representing a net loss term for larvae. For example, larvae may be advected offshore before they have the opportunity to be transported into a bay (Shanks et al. 2003).

The purpose of the present study was to investigate the effect of coastline configuration on larval assemblages by sampling a number of bays representing a gradient of flushing times. Estimates of larval diversity were compared from individual dates and, as an average, across months. Flushing time was used as a predictor variable. System-wide flushing time estimates are useful approximations for comparative studies, but such estimates contain errors due to an incomplete description of transport processes (Sheldon \& Alber 2006). We therefore augmented flushing time estimates with other potential predictor variables in a multivariate approach.

\section{MATERIALS AND METHODS}

Sampling. Replicate sea surface trawls were conducted in 8 bays along the Irish coast: Waterford Harbour, Wexford Harbour, Youghal Harbour, Cork Harbour, Tragumna Bay, Tranabo Bay, Strangford Lough and Roaringwater Bay (Fig. 1). Admiralty charts for the bays showed that they varied in area and depth, effectively generating a range of flushing times. In each bay, 2 sea surface plankton trawls were conducted from a $5 \mathrm{~m}$ rigid inflatable boat, each over approximately $400 \mathrm{~m}$ at an average speed of 1 to 2 knots, as gauged by an onboard global positioning system (GPS). Trawls were conducted monthly from March to June 2005 to coincide with the spring to summer zooplankton bloom, with each trawl utilising a buoyed $40 \mathrm{~cm}$ diameter conical net of $200 \mu \mathrm{m}$ mesh with attached flowmeter (General Oceanics Model 2030R with standard rotor). All trawls were performed during daylight hours, avoiding times of dawn and dusk to minimise the effect of diurnal vertical migration of larvae (Lampert 1989).

Sampling logistics require a compromise between replication in time at a site (e.g. González-Gordillo et al. 2003) and spatial replication across sites. We therefore sampled at a single time of day, but repeated this over 8 bays. To minimise potential bay-to-bay differences in species present due to sampling through the water column in bays of differing depth regimes (e.g. $66 \mathrm{~m}$ in Strangford Lough, $4 \mathrm{~m}$ in Wexford Harbour), sea surface trawls were performed. This undersamples the assemblage in each bay, particularly if species are undergoing diel vertical migrations and are more abundant in surface waters at night. Although such migration patterns exist in coastal waters, they are far from universal. Rawlinson et al. (2004) reported that $40 \%$ of meroplankton groups showed evidence of vertical migration, and these patterns were not consistently observed. In a study of crab larvae, GonzálezGordillo et al. (2003) found interspecific variability in the degree of vertical migration. Even species undergoing vertical migrations were rarely absent from surface waters (González-Gordillo et al. 2003, their 


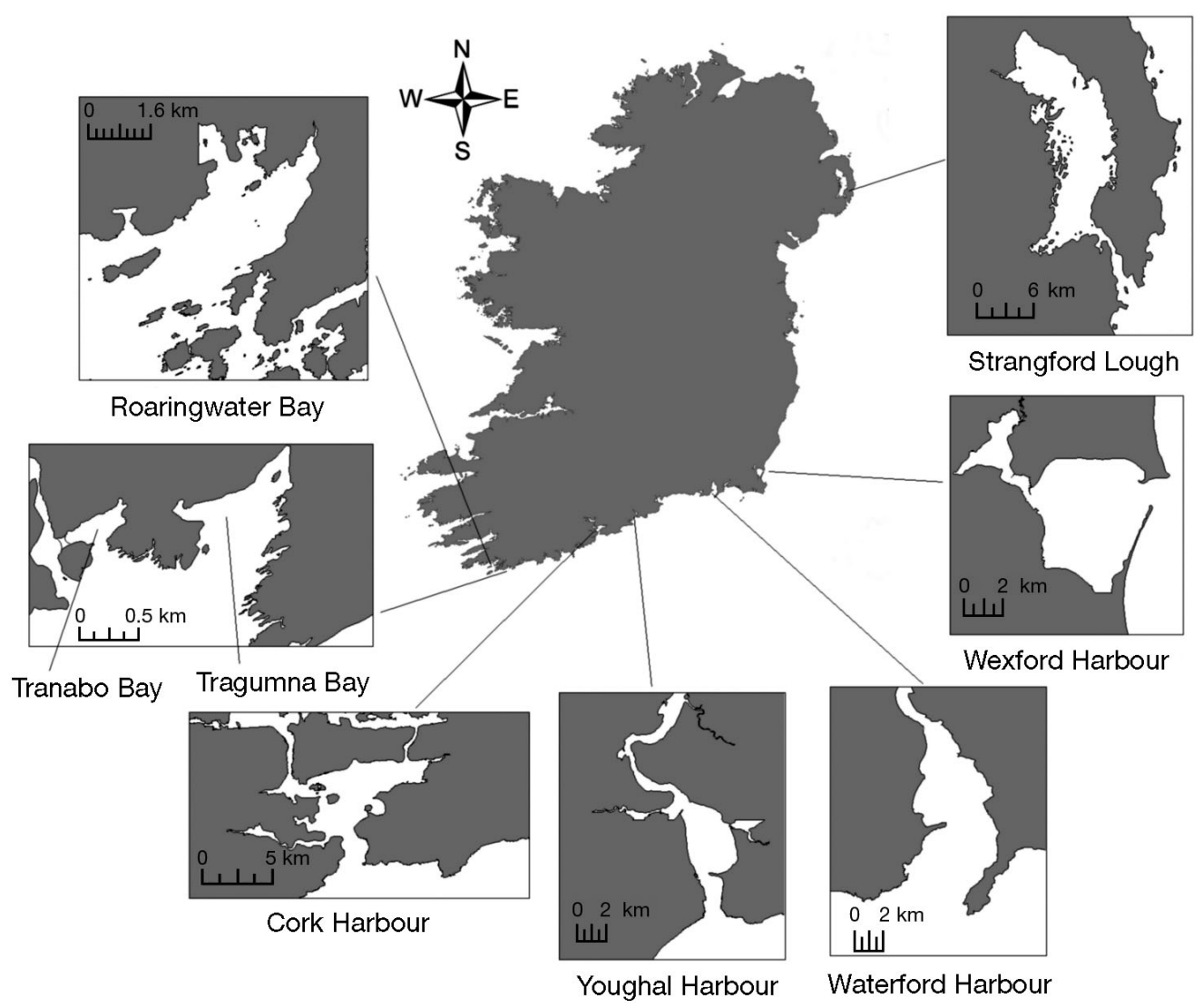

Fig. 1. Bays sampled along the Irish coast

Fig. 4). We therefore feel that daytime sampling provides a reliable estimate of the potential species pool. Variation among sites in vertical migration patterns may, however, complicate comparisons of relative abundance.

Samples were sieved through a $200 \mu \mathrm{m}$ mesh sieve and preserved in $100 \mathrm{ml}$ of $70 \%$ ethanol within $1 \mathrm{~h}$ of collection. Subsamples in aliquots of 1 to $5 \mathrm{ml}$ were taken using a bulb pipette to yield a sample containing approximately 300 individuals (Venrick 1971, Omori \& Ikeda 1992) for identification. Planktonic larvae of benthic marine invertebrates were identified to the lowest possible taxonomic level. Abundances were adjusted to reflect the volume of water sampled in each trawl, determined by flowmeter readings, and are given as the number of individuals per cubic metre (ind. $\mathrm{m}^{-3}$ ).

The flushing time $\left(T_{\mathrm{E}}\right)$ of each bay was estimated using the tidal prism method, applicable where only basin geometry and tidal range information are available, following Gillibrand (2001):

$$
T_{\mathrm{E}}=0.52 \frac{V+0.7 A R}{0.7 A R} \text { days }
$$

where $V$ is the volume of the bay at low water $\left(\mathrm{m}^{3}\right), A$ is the surface area of the bay at mid-tide $\left(\mathrm{m}^{3}\right)$ and $R$ is the mean spring tidal range $(\mathrm{m})$. The mean tidal range in the northeast Atlantic is typically a factor of 0.7 of the mean spring range and is the factor adopted here. The conversion factor of 0.52 accounts for the fact that there are 1.93 semi-diurnal tides $\mathrm{d}^{-1}$. Admiralty charts for each bay were digitised in GIS software (ARCGIS 8.2), with volume and surface area calculated from 3-dimensional models of the bays based on bathymetry. Mean spring tidal range was estimated using freely available tidal prediction software (JTides, www.arachnoid.com/JTides/index.html and Easytide, http://easytide.ukho.gov.uk).

Flushing time estimated by the tidal prism method is a simple metric to compare bays. By adding an appropriate 'return factor' to describe the proportion of embayment water returned on the flood tide, tidal prism methods can produce flushing estimates comparable to more complex models (Gillibrand 2001). The tidal prism flushing time (3 d) for the area of Strangford, where samples were taken, is similar to the results from a 3-dimensional hydrodynamic model (4 d; Ferreira et al. 2007). Simple measures of bay 
geometry may give a reasonable first approximation for properties such as a flushing time $\left(\mathrm{r}^{2}=52 \%\right.$ based on area and length; Abdelrhman 2005). The main disadvantage to simple estimates of flushing time is that they ignore various processes that affect flushing (Luketina 1998, Monsen et al. 2002). For example, there may be density-driven exchange, wind-driven advection of surface waters and variation within the system in flushing time. The temporal and spatial variability of such processes means that simple flushing time estimates are always extrapolations with unknown degrees of error. Unfortunately, the costs of routine application of more accurate estimates of flushing are prohibitive (Abdelrhman 2005). While recognizing the method's limitations, we used tidalprism-based estimates to compare embayments. Deviations from the assumptions of the tidal prism method do not consistently result in under- or overestimates of flushing. We therefore anticipate that the unknown error in our estimates of flushing is more likely to obscure predictive relationships than to cause them.

To include as much information on the systems as possible, we also used the following predictor variables: latitude, volume, area, area:volume ratio, tidal range, salinity, mean surface temperature (data freely available from www.emc.ncep.noaa.gov/research/cmb/ sst_analysis/) and mean chlorophyll a concentration (data available from http://reason.gsfc.nasa.gov/OPS/ Giovanni/ocean.seawifs.2.shtml\#description). Volume and area contain information about the size of the system and the potential local supply of larvae. Temperature and latitude are indicators of the potential differences in regional larval pools (for example, between the Irish and Celtic Seas). Salinity, chlorophyll and tidal range supply additional information on local productivity, magnitude of tidal supply and potential for density-driven circulation.

Data analysis. The influences of flushing time and the other environmental predictors on the local species pool were estimated using regression. Significant relationships with daily averages $(n=32)$ of species richness, Shannon diversity $\left(\log 2 H^{\prime}\right)$, evenness and abundance imply support for either hypothesis 2 or 3 as outlined in the introduction (the physical characteristics of bays influence the larval pool). In addition, the total species richness for each embayment was derived $(\mathrm{n}=8)$ and used as an estimate of the larval pool over the 4 mo sample period.

There is some redundancy among the environmental variables as predictors of the larval pool. For example, volume and area are likely to be at least partially correlated. With a relatively small number of bays in relation to the number of potential predictor variables, this colinearity can make multiple regression estimates unreliable (Quinn \& Keough 2006). We therefore used principle components analysis (PCA) as a data reduction technique to produce composite variables describing the overall patterns of environmental variability between bays. PCA transforms the pattern of variability in multivariate data into a series of orthogonal (uncorrelated) variables. Commonly the first 2 principle components describe the majority of the variability in a data set. The components can be used as orthogonal predictors without the problems associated with colinearity in the raw predictor variables. If the additional information across all environmental variables helps explain the differences in larval pool measures between sites, then the $\mathrm{r}^{2}$ values using PCA scores will be higher than $\mathrm{r}^{2}$ values from the best single predictor variable regression.

The turnover in species between separate sampling dates is an important descriptor of the larval pool. Great variability from week to week in the composition of the larval pool increases the potential number of species that may recruit to a site. Furthermore, large interspecific differences in larval abundance increase the opportunities for coexistence through variable recruitment. Three measures of this turnover were used. The simplest is the total number of species recorded from a bay (total species richness). Temporal turnover in species composition can also be measured by the average similarities between dates at a site (also known as measures of dispersion or beta diversity). This was calculated using Bray-Curtis similarities between dates. One analysis used presence/absence data to emphasize changes in species' identities. A second analysis used untransformed data to emphasize changes in larval abundance.

\section{RESULTS}

Bays represented a range of flushing times from $<1 \mathrm{~d}$ (Tranabo Bay, Youghal Harbour) to $3 \mathrm{~d}$ (Strangford Lough) (Table 1). PCA analysis of environmental variables emphasized the relative distinctiveness of Strangford Lough and Wexford Harbour (Fig. 2a). The first 2 principal components were associated with $81.4 \%$ of the variability among sites. The first component (PC1) has larger positive values for bays with greater volumes, higher latitudes, cooler temperatures and larger areas. There is also some association along PC1, with longer flushing times and greater phytoplankton biomass. The position of bays with respect to the second principal component (PC2) mostly reflects differences in salinity, tidal range and the average depth. Positive PC2 scores imply deeper bays with large tidal ranges and relatively high salinity. There is also some association with flushing time and chlorophyll, but unlike PC1, greater phytoplankton abun- 
dance is not associated with longer flushing times. PC2 tends to discriminate Wexford and Youghal as slightly shallower, less saline systems in comparison to bays with a more 'marine' character.

A total of 51 separate taxa were identified in samples, with the most common species being Elminius modestus, Pilumnus hirtellus, Necora puber, Verruca stroemia, Balanus crenatus, Littorina littorea, Electra pilosa, Mytilus spp., barnacle cyprid larvae and spionid worm trochophores. Flushing time was the best univariate predictor of the species richness observed on any particular day (significant regression; Fig. 3). The additional variables within the principal components slightly improved the level of variance in species richness explained $\left(\mathrm{r}^{2}\right.$ for PC2 was $39.1 \%$ compared to $34.5 \%$ for flushing time; Fig. 3a). The position of bays on PC2 also had significant relationships with Shannon diversity and evenness. Hence, a more marine nature of bays tended to imply a more diverse and richer assemblage, with a lower level of dominance by the most abundant species. In contrast to species richness, the best univariate predictor of diversity and evenness was salinity. There were no significant relationships between univariate or PCA predictors and the overall larval abundance.

Patterns for species richness in single-day samples were repeated when aggregating data across all dates at a bay (Fig. 4a). Positive PC2 scores were associated with higher species richness, although the best univariate predictor was salinity, not flushing time. Untransformed species counts showed a greater similarity among dates as PC2 scores increased. Bays with a more marine character, therefore, had a more stable larval assemblage over time. This stability was caused by consistencies in species abundances rather than the identities of species. Turnover in species' identities (similarity based on presence/absence) had no consistent relationship with environmental predictors (Fig. 4c).

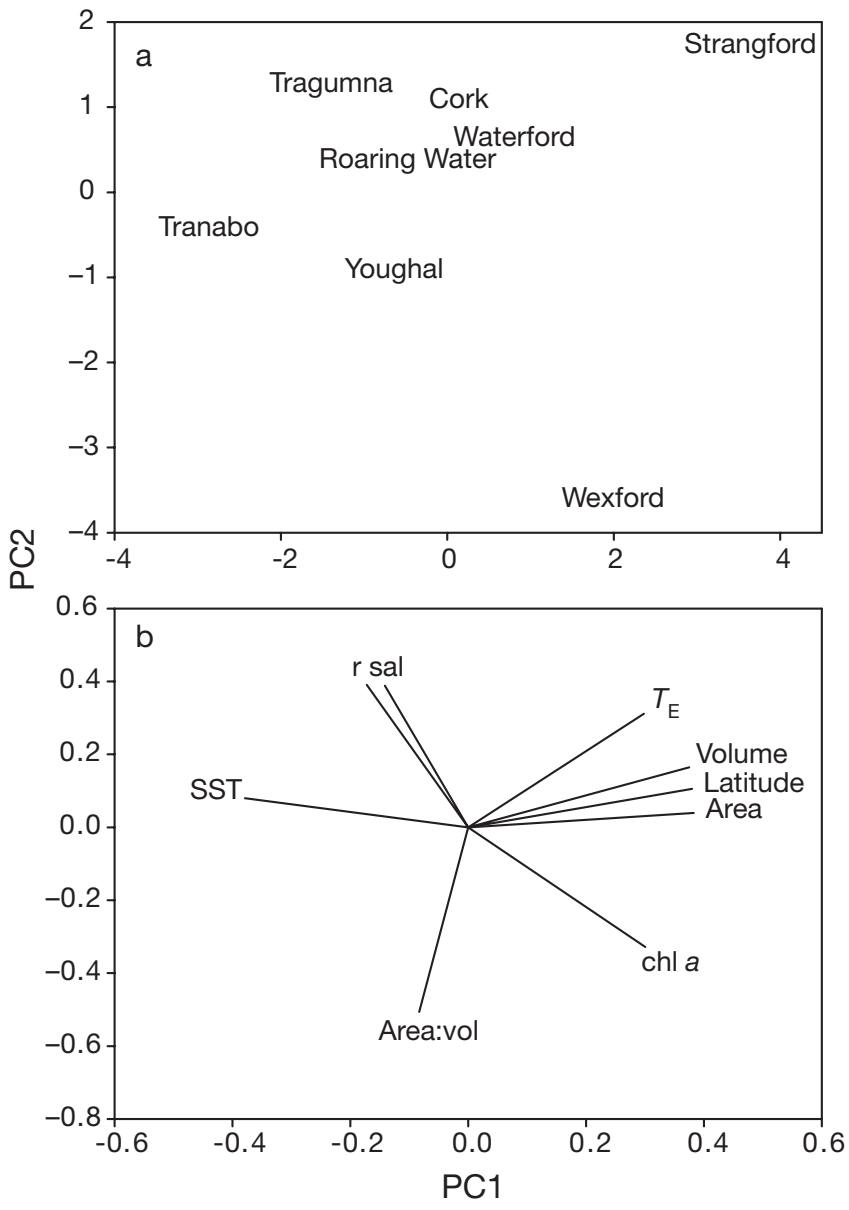

Fig. 2. Principal component analysis of bays by environmental variables. (a) The relative positions of bays along the first 2 principal components (PC1 and PC2; accounting for $81.4 \%$ of the variation among sites). (b) Contributions of individual variables to component scores along each axis. Variables contribute little to an axis to which they are perpendicular. Positively correlated variables have similar vectors. Negatively correlated variables have diametrically opposed vectors (e.g. SST and latitude). SST: sea surface temperature; $r$ : tidal range; sal: salinity; $T_{\mathrm{E}}$ : estimated flushing time; area:vol: area divided by volume, higher in relatively shallow systems

Table 1. Environmental variables of studied embayments. Flushing time of bays was calculated using the tidal prism method

\begin{tabular}{|lcccccccc|}
\hline Bay & $\begin{array}{c}\text { Flushing } \\
\text { time }\left(T_{\mathrm{E}}\right) \\
(\mathrm{d})\end{array}$ & $\begin{array}{c}\text { Latitude } \\
\left({ }^{\circ} \mathrm{N}\right)\end{array}$ & $\begin{array}{c}\text { Tidal } \\
\text { range } \\
(\mathrm{m})\end{array}$ & $\begin{array}{c}\text { Average } \\
\text { surface temp. } \\
\left({ }^{\circ} \mathrm{C}\right)\end{array}$ & $\begin{array}{c}\text { Volume } \\
\left(\mathrm{m}^{3} \times 10^{6}\right)\end{array}$ & $\begin{array}{c}\text { Area } \\
\left(\mathrm{m}^{2} \times 10^{6}\right)\end{array}$ & $\begin{array}{c}\text { Mean } \\
\text { salinity }\end{array}$ & $\begin{array}{c}\text { Mean } \\
\text { chlorophyll conc. } \\
\left(\mathrm{mg} \mathrm{m}^{-3}\right)\end{array}$ \\
\hline Tranabo Bay & 0.89 & $51^{\circ} 29^{\prime} 46^{\prime \prime}$ & 3.48 & 11.65 & 0.15 & 0.09 & 34.4 & 1.13 \\
Youghal Harbour & 0.94 & $51^{\circ} 58^{\prime} 12^{\prime \prime}$ & 3.42 & 11.3 & 5.76 & 2.96 & 21.4 & 1.35 \\
Wexford Harbour & 1.25 & $52^{\circ} 20^{\prime} 10^{\prime \prime}$ & 1.27 & 10.92 & 24.30 & 19.51 & 18.6 & 5.20 \\
Waterford Harbour & 1.30 & $52^{\circ} 20^{\prime} 10^{\prime \prime}$ & 3.81 & 10.92 & 92.88 & 23.30 & 26.1 & 1.37 \\
Roaringwater Bay & 1.33 & $51^{\circ} 32^{\prime} 08^{\prime \prime}$ & 2.65 & 11.65 & 29.83 & 10.27 & 35 & 1.08 \\
Cork Harbour & 1.72 & $51^{\circ} 50^{\prime} 17^{\prime \prime}$ & 3.70 & 11.57 & 115.44 & 19.37 & 28.4 & 1.71 \\
Tragumna Bay & 1.86 & $51^{\circ} 29^{\prime} 53^{\prime \prime}$ & 3.48 & 11.65 & 3.23 & 0.52 & 34.4 & 1.13 \\
Strangford Lough & 3.00 & $54^{\circ} 23^{\prime} 17^{\prime \prime}$ & 2.99 & 10.63 & 924.94 & 92.49 & 32.6 & 3.13 \\
\hline
\end{tabular}



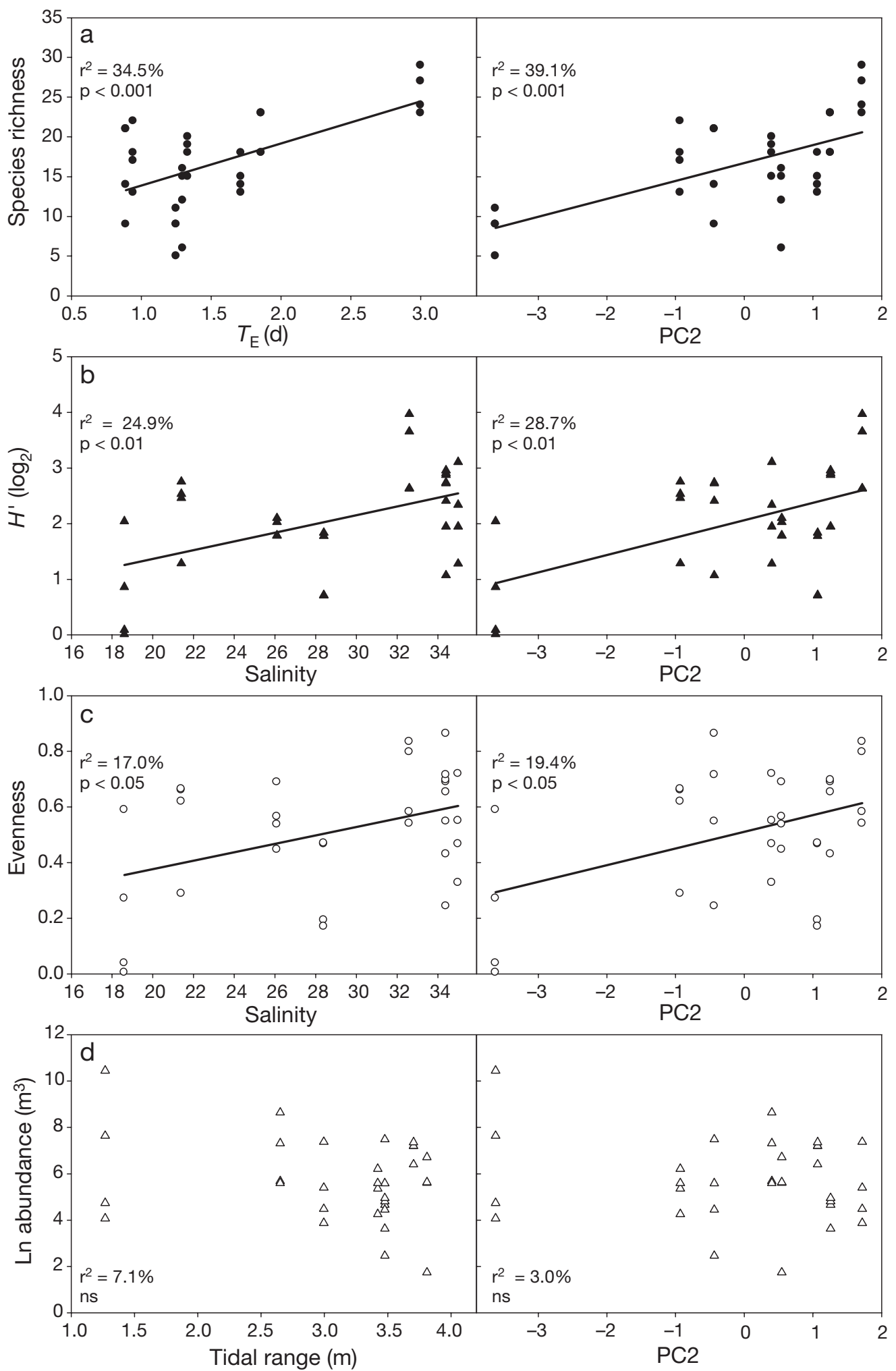

Fig. 3. Simple linear regressions of environmental variables against: (a) species richness (no. of taxa), (b) Shannon-Wiener diversity $\left(H^{\prime}\right)$, (c) evenness and (d) ln-transformed abundance. Points represent individual sampling dates $(\mathrm{n}=4)$ in each system. Panels on the left-hand side show the single environmental variable with the greatest predictive power (highest $\mathrm{r}^{2}$ ). Right-hand panels show the principal component scores (Axis 1 or 2) with the highest predictive power. Regression lines are only drawn for statistically significant relationships. $T_{\mathrm{E}}$ : estimated flushing time; ns: not significant 

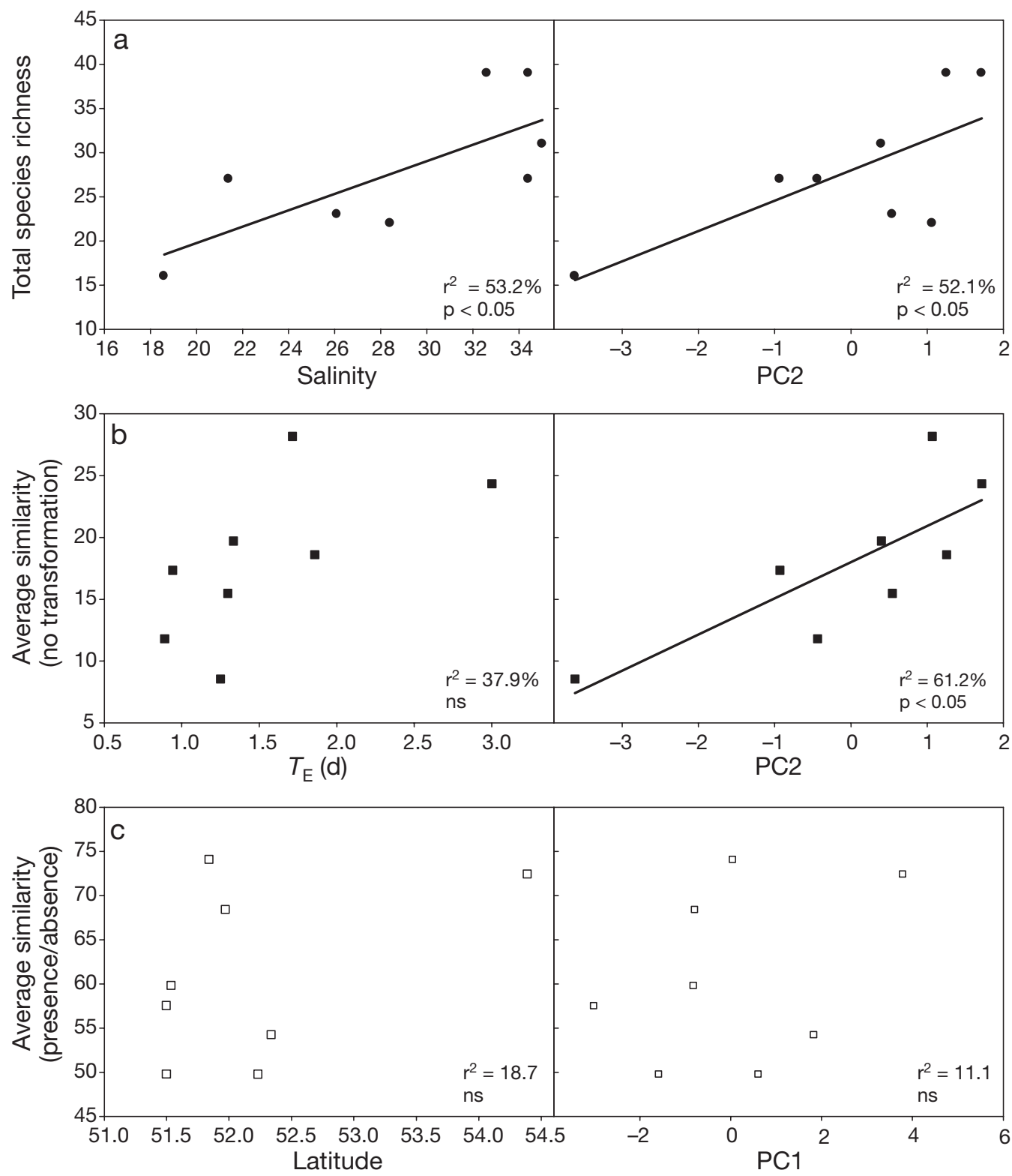

Fig. 4. Associations between larval pool characteristics calculated across sample dates and potential environmental predictor variables. (a) Total species richness (no. of taxa) from each bay; (b) average similarity between dates within each bay, without transforming the data; and (c) average similarity between dates, using presence/absence data only. In each case the best single variable prediction is shown in the left-hand panel and the best compound (principal components based) predictor variable is in the right-hand panel ( $\mathrm{r}^{2}$ values used for ranking of relationships). Regression lines are only drawn for statistically significant relationships. $T_{\mathrm{E}}$ : estimated flushing time; ns: not significant

\section{DISCUSSION}

There was clear evidence that the physical characteristics of bays influence the local larval pool. Species richness was higher in bays with longer flushing times (hypothesis 3). If transport away from the coast reduces larval and adult abundance (Shanks et al. 2003), bays with a longer flushing time should retain more larvae than bays with a short flushing time, resulting in increased abundances and a higher diversity. There was, however, no evidence for low larval densities in water outside bays: larval abundances were not affected by environmental variables. Upwelling-related transport has been suggested as a cause of low larval densities in coastal waters (although this may not be a general mechanism of larval transport; Shanks \& Brink 2005). The sampled bays were not on coasts subject to strong upwelling influences. 
The unknown errors in tidal-prism-based estimates of flushing may have influenced the results in 2 ways. Either the errors caused the flushing time estimates to correlate with some other feature of bays that underlies the patterns, or, despite the errors, tidal prism estimates of flushing retain sufficient information on the relative contribution of inputs from outside the bays to have some predictive power. The PCA results discussed below give some indication on a gradient of bay types that may underlie the observed patterns. If tidal flushing estimates were of themselves important, one would expect that more accurate estimates of flushing would improve the proportion of variance explained in the regressions.

One of the dominant patterns among bays identified in the PCA was a gradient from more saline bays with long flushing times to less saline embayments with shorter flushing times. The positions of bays along this gradient (PC2) generally explained more variation in the larval pool than univariate predictors such as flushing time or salinity. Potential mechanisms behind the increasing species richness with higher PC2 scores are: (1) deeper bays have more habitat diversity than shallow bays, leading to a more diverse potential source of larvae, and (2) species richness is correlated with salinity. As more saline bays contain more marine species, this leads to a more diverse larval pool.

Gaines \& Bertness (1992) suggested that variability in recruitment may be due to variable larval retention, and correlated settlement of the barnacle Semibalanus balanoides to variation in flushing time and offshore transport of larvae in Narragansett Bay. Flushing time in Narragansett Bay was estimated from riverine inflow, emphasizing the estuarine nature of the bay. We found that larval assemblages were more variable over time in the shallower, more estuarine sites (low PC2 scores). This is consistent with Gaines \& Bertness' (1992) conclusion that larval concentrations are more variable in bays more influenced by freshwater input.

The positive relationship between both species richness and flushing time contrasts with the study by $\mathrm{Su}$ et al. (2004), who found no effects of tidal flushing on phytoplankton species richness or diversity in a tropical lagoon. However, McKindsey \& Bourget (2000) found increased species richness with increasing bay size, noting highest values along straight coasts, and Archambault \& Bourget (1999) reported increased benthic diversity with increasing size of bay. In those 2 studies, selection of bays was based on the length being smaller than the width of the aperture, such that the increasing size of a bay resulted in increasingly open areas resembling straight coastline (shorter flushing). In the current study, bay length was always greater than the width of the aperture, and a positive relationship between volume and flushing time was found. Increasing bay size reflected larger indentations into the coastline and increased water retention. The contrast between our results and the observations of shorter flushing being associated with higher species richness (Archambault \& Bourget 1999, McKindsey \& Bourget 2000) may therefore reflect the trend for the larger systems in both studies to contain more biotopes and associated species.

Multivariate analysis of communities, comparing untransformed and presence/absence data, highlighted the importance of changes in abundance in contributing to multivariate dispersion. Regression analysis showed that bays with higher PC2 scores had lower multivariate dispersion than bays with short flushing times, suggesting that part of the same population of larvae was sampled on different dates. This may lead to more predictable recruitment patterns and a greater stability of community composition over time. Such stability will also be reflected in greater selfrecruitment in bay populations. This prediction is supported by findings that short flushing mixes larvae from a variety of sources, while long flushing times may lead to restricted gene flow and adaptation to local conditions in barnacles (Bertness \& Gaines 1993).

In a study of 8 bays, not all potential combinations of environmental variables can be investigated. For example, it might be interesting to measure the larval pool of shallow saline and deep brackish systems. This may help to separate the relative contributions of habitat diversity and salinity to species richness. The absence of these types from our analysis may, however, reflect the underlying geomorphological processes giving rise to embayments.

The present study has shown that environmental variables used to characterize coastline configuration, latitude and availability of phytoplankton can be used as predictors of species richness, diversity and structure of larval assemblages. Our results suggest that flushing time is an important factor in regulating the diversity of the larval pool. The next step is to test whether prediction of the characteristics of the larval pool allows prediction of the diversity and variability of recruitment and, potentially, the resistance of systems to invasive species (Herben 2005).

Acknowledgements. The authors thank P. Johnston and G. Savidge (Portaferry Marine Laboratory), R. Thomas and A. Dale (University College Cork) for valuable field assistance. This research was conducted as part of the MARDEM collaboration between Queens University Belfast, University College Dublin and University College Cork, with funding from the Irish Higher Education Authority, under Strand 1 of the North-South Programme for Collaborative Research, which was supported by the National Development Plan 2000-2006. The manuscript benefited from the comments of 3 anonymous reviewers. 


\section{LITERATURE CITED}

Abdelrhman MA (2005) Simplified modeling of flushing and residence times in 42 embayments in New England, USA, with special attention to Greenwich Bay, Rhode Island. Estuar Coast Shelf Sci 62:339-351

Alldredge AL, Hamner WM (1980) Recurring aggregation of zooplankton by a tidal current. Estuar Coast Mar Sci 10: 31-37

Archambault P, Bourget E (1999) Influence of shoreline configuration on spatial variation of meroplanktonic larvae, recruitment and diversity of benthic subtidal communities. J Exp Mar Biol Ecol 241:309-333

Archambault P, Roff JC, Bourget E, Bang B, Ingram GR (1998) Nearshore abundance of zooplankton in relation to shoreline configuration and mechanisms involved. J Plankton Res 20:671-690

Bertness MD, Gaines S (1993) Larval dispersal and local adaptation in acorn barnacles. Evolution 47:316-320

Chesson PA (1985) Coexistence of competitors in spatially and temporally varying environments: a look at the combined effects of different sorts of variability. Theor Popul Biol 28:263-287

Cowen RK, Paris CB, Srinivasan A (2006) Scaling of connectivity in marine populations. Science 311:522-527

Ferreira JG, Hawkins AJS, Monteiro P, Service M and 11 others (2007) SMILE — Sustainable Mariculture in Northern Irish Lough Ecosystems-Assessment of carrying capacity for environmentally sustainable shellfish culture in Carlingford Lough, Strangford Lough, Belfast Lough, Larne Lough and Lough Foyle. IMAR - Institute of Marine Research, Coimbra, Portugal, available at: www.ecowin. org/smile/documents/smile\%20book.pdf

Gaines SD, Bertness MD (1992) Dispersal of juveniles and variable recruitment in sessile marine species. Nature 360: 579-580

Gillibrand PA (2001) Calculating exchange times in a Scottish fjord using a two-dimensional, laterally-integrated numerical model. Estuar Coast Shelf Sci 53:437-449

González-Gordillo JI, Arias AA, Rodríguez A, Drake P (2003) Recruitment patterns of decapod crustacean megalopae in a shallow inlet (SW Spain) related to life history strategies. Estuar Coast Shelf Sci 56:593-607

Herben T (2005) Species pool size and invasibility of island communities: a null model of sampling effects. Ecol Lett 8: 909-917

Knights AM, Crowe TP, Burnell G (2007) Mechanisms of larval transport: vertical distribution of bivalve larvae varies with tidal phase and state. Mar Ecol Prog Ser 326:167-174

Lampert W (1989) The adaptive significance of diel vertical migration of zooplankton. Funct Ecol 3:21-27

Lobel PS, Robinson AR (1986) Transport and entrapment of fish larvae by ocean mesoscale eddies and currents in Hawaiian waters. Deep-Sea Res Part A 33:483-500

Luketina D (1998) Simple tidal prism models revisited. Estuar Coast Shelf Sci 46:77-84

McCulloch A, Shanks AL (2003) Topographically generated fronts, very nearshore oceanography and the distribution and settlement of mussel larvae and barnacle cyprids. J Plankton Res 25:1427-1439

McKindsey CW, Bourget E (2000) Explaining mesoscale variation in intertidal mussel community structure. Mar Ecol Prog Ser 205:155-170

Monsen NE, Cloern JE, Lucas LV, Monismith SG (2002) A comment on the use of flushing time, residence time, and age as transport time scales. Limnol Oceanogr 47:1545-1553

Omori M, Ikeda T (1992) Methods in marine zooplankton ecology. Krieger publishing company, Malabar, FL

Palma AT, Pardo LM, Veas R, Cartes C and 5 others (2006) Coastal brachyuran decapods: settlement and recruitment under contrasting coastal geometry conditions. Mar Ecol Prog Ser 316:139-153

Palumbi SR (2003) Population genetics, demographic connectivity, and the design of marine reserves. Ecol Appl 13: $146-158$

Paris CB, Cowen RK (2004) Direct evidence of a biophysical retention mechanism for coral reef fish larvae. Limnol Oceanogr 49:1964-1979

Prandle D (1984) A modelling study of the mixing of $137 \mathrm{Cs}$ in the seas of the European continental shelf. Philos Trans R Soc Lond A 310:407-436

Quinn GP, Keough MJ (2006) Experimental design and data analysis for biologists. Cambridge University Press, Cambridge

Rawlinson KA, Davenport J, Barnes DKA (2004) Vertical migration strategies with respect to advection and stratification in a semi-enclosed lough: a comparison of meroand holozooplankton. Mar Biol 144:935-946

Shanks A, Brink L (2005) Upwelling, downwelling, and crossshelf transport of bivalve larvae: test of a hypothesis. Mar Ecol Prog Ser 302:1-12

Shanks AL, McCulloch A, Miller J (2003) Topographically generated fronts, very nearshore oceanography and the distribution of larval invertebrates and holoplankters. J Plankton Res 25:1251-1277

Sheldon JE, Alber M (2006) The calculation of estuarine turnover times using freshwater fraction and tidal prism models: a critical evaluation. Estuar Coasts 29:133-146

Sponaugle S, Cowen RK, Shanks A, Morgan SG and others (2002) Predicting self-recruitment in marine populations: biophysical correlates and mechanisms. Bull Mar Sci 70:341-375

Strathmann RR, Hughes TR, Kuris AM, Lindeman KC, Morgan SG, Pandolfi JM, Warner RR (2002) Evolution of local recruitment and its consequences for marine populations. Bull Mar Sci 70:377-396

Su HM, Lin HJ, Hung JJ (2004) Effects of tidal flushing on phytoplankton in a eutrophic tropical lagoon in Taiwan. Estuar Coast Shelf Sci 61:739-750

Venrick EL (1971) Statistics of subsampling. Limnol Oceanogr 16:811-818

Zobel M (1997) The relative role of species pools in determining plant species richness. An alternative explanation of species coexistence? Trends Ecol Evol 12:266-269

Submitted: October 23, 2006; Accepted: July 12, 2007

Proofs received from author(s): November 14, 2007
Editorial responsibility: Steven Morgan (Contributing Editor), Bodega Bay, California, USA 